\title{
Scheduling of Machines and AGVs Simultaneously in FMS through Hybrid Teaching Learning Based Optimization Algorithm
}

\author{
Kanakavalli Prakash Babu, Vommi Vijaya Babu, Medikondu Nageswara Rao
}

\begin{abstract}
The most complex problem in FMS is scheduling task, due to this complexity it has created interest among many researchers. Even though FMS scheduling problem was considered earlier, material handling systems like (AGVs) scheduling was not done effectively. As transportation times cannot be neglected in an FMS, a carefully managed and designed material handling system is important in achieving the required integration in flexible manufacturing environment. Hence there is a need for scheduling both the machines and material handling system simultaneously for the successful implementation of an FMS, which makes the scheduling of FMS more complex. Metaheuristic Algorithms are mostly received by the researchers, because of their capability to tackle more complex problems. Hybridization of the metaheuristics may further improve their performance. In the present work a new hybrid metaheuristic Teaching Learning based optimization(HTLBO) is proposed to solve simultaneous scheduling problems.

Keywords : AGVs, FMS, Operational Completion Time (makespan), Metaheuristic algorithms, , NP-hard problems
\end{abstract}

\section{INTRODUCTION}

Producing wide variety of parts in low to mid volume quantities at a low cost while maintaining a good quality in end items is one of the characteristic of Flexible Manufacturing System (FMS).FMS executed number of benefits in terms of cost reduction- increased machine utilization - reduced work-in -process levels- etc. Howeverthere are many problems encountered during the life cycle of an FMS and these are classified into: design- planningscheduling- and controlling. In particular- the scheduling task and control problem during the manufacturing operation are of importance owing to the dynamic nature of the FMS in respect of flexible parts- tools- assignments. In FMS not only sequencing of jobs on machines

Revised Manuscript Received on December 30, 2019.

* Correspondence Author

Kanakavalli Prakash Babu*, Department of Mechanical V. R. Siddhartha Engineering, College Vijayawada, Visakhapatnam, Andhra Pradesh. India, Email: prakashmim06@gmail.com

Vommi Vijaya Babu, Department of Mechanical A.U. College of Engineering, (A), Andhra University, Visakhapatnam, Andhra Pradesh. India , Email: vijayababu63@gmail.com

Medikondu Nageswara Rao, Department of Mechanical KLEF University, Vaddeswaram , India. Email: medikondu@kluniversity.in

(c) The Authors. Published by Blue Eyes Intelligence Engineering and Sciences Publication (BEIESP). This is an open access article under the CC BY-NC-ND license (http://creativecommons.org/licenses/by-nc-nd/4.0/)
But also the routing of the jobs through the system must be taken into consideration. Apart from the machines- other resources in the system like Automated Guided Vehicle (AGV) and Automated Storage/Retrieval System (AS/RS) must be considered The AGVs effectiveness depends on vehicle management system.

\section{LITERATURE REVIEW}

\section{A. Simultaneous scheduling in FMS}

In simultaneous scheduling- the real time as well as the off-line scheduling is taken into account. Bilge and Ulusoy [1] exploited the interactions between the machine and AGVs scheduling simultaneously. The material transfer between machines is done by a number of identical AGVs which are not allowed to return to the load/unload station after each delivery. Abdelmaguid et al.[2] suggested a hybrid GA for minimizing the makespan. The algorithm is implemented to a set of 82 test problems- which was constructed by other researchers- and the comparison of the results indicates the superior performance with the developed coding. Reddy and Rao [3] studied the simultaneous scheduling problem with makespan- mean flow time and mean tardiness as an criterion. The proposed hybrid GA for FMS scheduling problems yielded better results when compared to other algorithms. Gnanavelbabu et al. [4] examined simultaneous scheduling in FMS using DE with makespan minimization. Anandaraman et al. [5] presented a solution for the simultaneous scheduling problem by evolutionary approach in FMS with vehicles and robots.The scheduling optimization is carried out using metaheuristic algorithm. The algorithms are implemented for bench mark problems taken from the literature and the comparision is also done. Nouri et al. [6] introduced the clustered holonic multiagent model using metaheuristic for simultaneous scheduling of machines and transport robot in FMS. Computational results are presented using three sets of benchmark instances in the literature. New upper bounds are found- showing the effectiveness of the presented approach. Md Kamal et al. [7] Flexible Job Shop Scheduling Problem (FJSSP) is an extension of the classical Job Shop Scheduling Problem (JSSP).

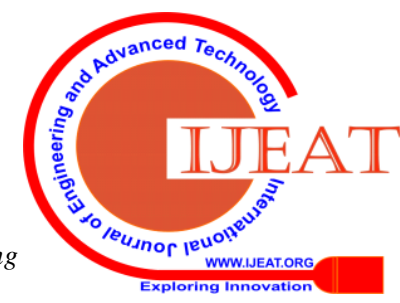


Keeping in view this aspect- this article presents a comprehensive literature review of the FJSSPs solved using the GA. The survey is further extended by the inclusion of the hybrid GA (HGA).Nageswara raoet al [8].

\section{SIMULTANEOUS SCHEDULING PROBLEMS IN FMS}

\section{A. Problem structure}

Bilge and Ulusoy (1995) proposed a numerical example for simultaneous scheduling of machines and AGVs in FMS environment which includes four layouts- ten jobsets process times and travel time data. This data is considered as input in the present work.

\section{B. Objective function}

Operation completion time $=\mathrm{Oij}=\mathrm{Tij}+\mathrm{Pij}$

$\mathrm{T}_{\mathrm{ij}}=$ Traveling time for $\mathrm{j}^{\text {th }}$ operation and $\mathrm{i}^{\text {th }} \mathrm{job}$

$\mathrm{P}_{\mathrm{ij}}=$ operation processing time

\section{Optimization parameters considered}

Population Size $=$ Double the no of operations Iterations completed $=1000$

\section{Vehicle Assignment Procedure}

It is required to schedule both material handling system and machines at a time in this problem. To obtain the makespan value for a given sequence of operations the following procedural steps are implemented.

Step 1: Consider the machine number (M.No) of the given sequence for the job.

Step 2: Select the AGV

Step 3: Identify the vehicle previous location (VPL)previous operation machine number (POMN)- vehicle ready time (VRT) and previous operation completion time (POCT)

Step 4: Calculate vehicle empty trip time (VET) using VET $=$ VRT+VPL to POMN

Step 5: Select the maximum among POCT and VET.

Step 6: Obtaining the total travel time of vehicle (TT) using $\mathrm{TT}=\mathrm{VET}+\mathrm{POMN}$ to M.No.

Step 7: Find the machine readiness time (MRT).

Step 8: Identify the maximum among TT and MRT.

Step 9: Maximum time (from step 8) is added to process time to get the operational completion time.

Step 10: Repeated the steps from 2 to 9 for all other operations.

Step 11: Identify the maximum operational completion timewhich represents the possible completion time (makespan) of given job set.

\section{TEACHING LEARNING BASED OPTIMIZATION}

Teaching Learning Based Optimization (TLBO) algorithm is proposed by Rao et al. (2011). It comprises two phases Teacher phase that is gaining knowledge through teacher and Learner phase gaining knowledge through learner to learner interaction. The steps involved in the algorithm are shown in the flow chart (Figure.1).

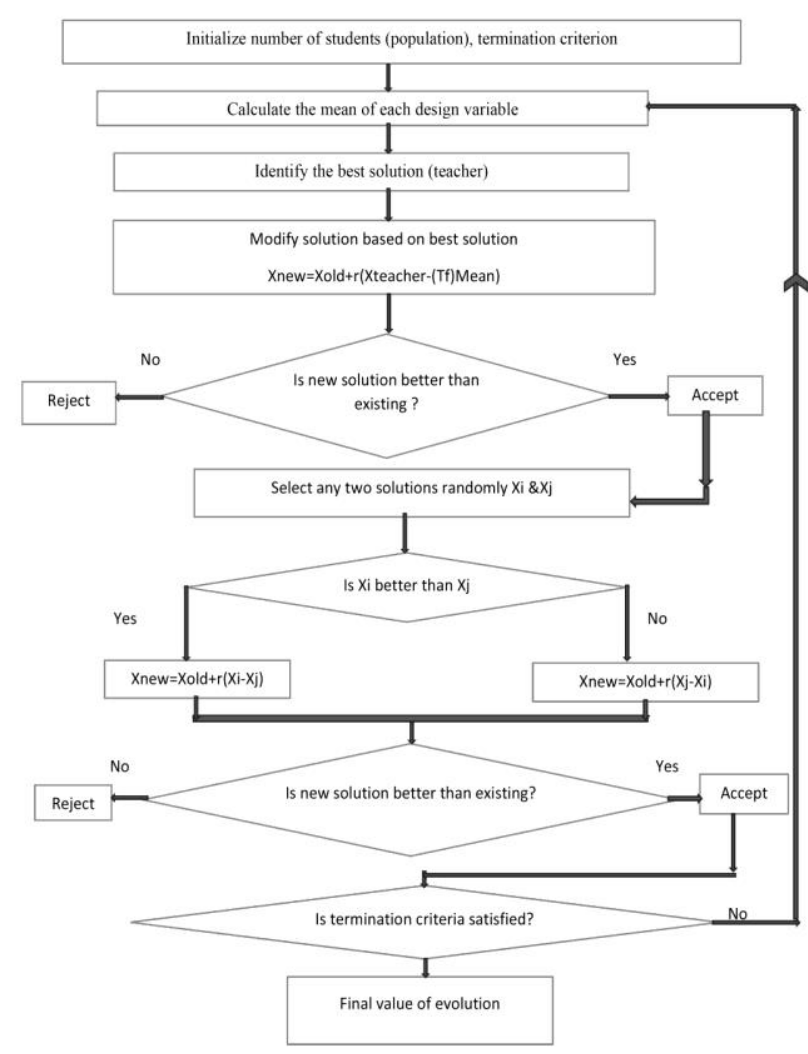

Figure.1: Flow chart for TLBO algorithm

\section{A. Hybrid Algorithms}

Since mixing of any two algorithms yields superior results, TLBO is amalgamated with Sheep Flock Heredity Algorithm.

\section{B. Sheep Flock Heredity Algorithm}

Sheep Flock Heredity Algorithm (SFHA) was developed by Hyunchul Kim (2001).This algorithm is based on the genetic inheritance.

The steps involved in SFHA are given below:

Step 1: Generate Initial population randomly.

Step 2: The desired optimization fitness is evaluated for each chromosome.

Step 3: Sub chromosome level crossover and mutation must be done

Step 4: Do the chromosome level crossover and mutation process by selecting the best chromosome from the population.

Step 5: Calculate the fitness function for each chromosome in the population. Then do the sorting function.

Step 6: After sorting the strings, to do the editing of the chromosomes in the population after the mutation process.

Step 7: After editing the chromosomes in the population the new population has to undergo next iteration until termination criterion is reached.

\section{Hybrid Teaching Learning Based Optimization}

Step 1: Consider the job set

Step 2: For the job set implement TLBO as explained in Section. IV to get the sequence of operation. 
Step 3: After getting the sequence of operation for each iteration, crossover and mutation concepts are to be implemented.

\section{Algorithm to Optimal Scheduling Problem}

For illustration of HTLBO, Job set 9 and Layout 1 are taken into consideration. Data related to jobset 9 is shown in Table.I. HTLBO algorithm computes the effect of the influence of a teacher on the output of learners in a class and receptor editing for different jobs and the sequences are obtained based on results or grades.

The HTLBO algorithm is illustrated below for job set 9:

Step 1: Considering the job set

In HTLBO for the operation in a job set numbers are assigned serially.

Step 2: Initializing the optimization parameters.

Teaching Factor, $\left(\mathrm{T}_{\mathrm{F}}\right)=1$ or 2 , Random number $=0$ to 1

Step 3: Initial population is generated randomly by following precedence relation, these are presented in table 1 . The makespan for each sequence is calculated to implement the steps discussed in article III section.D to identify the maximum operational completion time (makespan) for each sequence.

From the above table it can be interpreted that in $1^{\text {st }}$ sequence, number ' 8 ' represents $1^{\text {st }}$ operation on the job no 3 and similarly number ' 14 ' represents the $1^{\text {st }}$ operation on job no 5 . Similarly number ' $17^{\text {' }}$ represents $4^{\text {th }}$ operation on job no 5 and so on.

Step 4: Teacher phase.

A good teacher is one who brings his or her learners up to his or her level in terms of knowledge. But in practice this is not possible and a teacher can only raise the mean of a class up to some extent depending on the capability of the class. In the entire population, the best solution is considered as the teacher $\left(X_{\text {teacher }}\right)$. In the teacher phase the teacher tries to enhance the results of other individuals $\left(\mathrm{X}_{\mathrm{i}}\right)$ by increasing the mean result of the classroom $\left(\mathrm{X}_{\text {mean }}\right)$ towards his/her position ( $\left.\mathrm{X}_{\text {teacher }}\right)$. In order to maintain stochastic features of the search, two randomly-generated Parameters $\mathrm{r}$ and TF are applied in update formula for the solution $\mathrm{Xi}$ as:

$\mathrm{X}_{\text {New }}=\mathrm{X}_{\mathrm{i}}+\mathrm{r}\left(\mathrm{X}_{\text {Teacher }}-\mathrm{T}_{\mathrm{F}} * \mathrm{X}_{\text {Mean }}\right)$

Where $r$ is the random number considered between the range of 0 and 1 and

$\mathrm{T}_{\mathrm{F}}=$ Teaching factor which is considered as 1 or 2 :

$\mathrm{T}_{\mathrm{Fi}}=$ round $[1+$ rand $(0,1)\{2-1\}]$

Moreover, Xnew and $\mathrm{Xi}$ are the new and existing solution of i.

Mean of population is calculated

Mean $\left(\mathrm{X}_{\text {Mean }}\right)=$ Total make span /Total no of sequences

$$
=3699 / 34=145.2 \approx 145
$$

$=11-14-8-1-5-2-12-6-9-15-13-10-16-3-7-17-4$

The best solution will act as a teacher for that iteration

$\mathrm{X}_{\text {teacher }}=\mathrm{X}_{\mathrm{f}(\mathrm{X})=\text { min. }}$.

$X_{\text {teacher }}=8-14-5-11-1-9-12-6-15-2-10-16-3-7-13-4-17$

The difference between the $\mathrm{X}_{\text {Teacher }}$ and $\mathrm{X}_{\text {Mean }}$ is expressed as Difference, $\mathrm{D}=\mathrm{r}\left(\mathrm{X}_{\text {Teacher }}-\mathrm{T}_{\mathrm{F}} * \mathrm{X}_{\text {Mean }}\right)$.

$=0.85\{(8-14-5-11-1-9-12-6-15-2-10-16-3-7-13-4-17)-2 *$

(11- 14-8-1-5-2-12-6-9-15-13-10-16-3-7-17-4)\}

Subtracting the two vectors $X_{\text {Teacher }}$ and $X_{\text {Mean }}$ (absolute value is taken) and multiplying it with random number 0.85 and rounding off, we get
Difference, $\mathrm{D}=0.85\{(8-14$-5 -11- 1-9-12- 6-15- 2- 10-16- 3-

$7-13-4-17)$ - (22-28-16

$-2-10-4-24-12-18-30-26-20-32-6-14-34-8)\}$

Difference, D

$=0.85(14-14-11-9-9-5-12-6-3-28-16-4-29-1-1-30-9)$

Difference, ${ }_{\mathrm{D}}=$

(11.9-11.9-9.35-7.65-7.65-4.25-10.2-5.1-2.55-23.8-13.6-

3.4-24.65-0.85-0.85-25.5-7.65)

Difference, $\mathrm{D}=$ (12-12-9-8-8-4-10-5-3-24-14-3-25-1-1-25-8)

The $T_{F}$ value is considered as one or two. The difference obtained is added to the current solution to update its values using

$\mathrm{X}_{\text {new, } \mathrm{D}}=\mathrm{X}_{\text {old, } \mathrm{D}}+$ Difference, $\mathrm{D}$

For example $1^{\text {st }}$ sequence as $\mathrm{X}_{\text {old, }} \mathrm{D}$ is considered

$=(8-14-5-11-1-9-12-6-15-2-10-16-3-7-13-4-17)+$

(12-12-9-8-8-4-10- 5-3-24-14-3-25-1-1-25-8)

$\mathrm{X}_{\text {new,D }}=$

20-26-14-19-9-13-22-11-18-26-24-19-28-8-14-29-25

Convert the values above 17 to allow max value within the bounds.

$\mathrm{X}_{\text {new, D }}=$ 3- 9- 14- 2- 9- 13- 5- 11- 1- 9- 7- 2- 11- 8- 14- 12- 8 In the above sequence few operations are missing and some are repeated to handle this a corrected repair function is used. Thus the resulting sequence after repair is

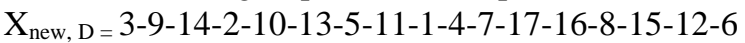

The above sequence is repaired by using a repair function, inorder to avoid repetitions and to follow precedence norms The resulting sequence after repair is shown below.

$\mathrm{X}_{\text {new }}=1$ - 8- 14- 2- 9- 11- 5- 12- 3- 4- 6- 15- 16- 10- 17- 13- 7 If the new sequence makespan value (after teacher phase) is less than that of the original sequence, then the new one is stored in place of the original one. In case if the algorithm was not able to find a better solution the original sequence remains the same.

Step 5: Learner Phase

Throughout this phase, the student $X i$ interacts randomly with another student $X_{j}$ (i j) in order to improve his/her knowledge. In the case that $X_{j}$ is better than $X_{i}$ i.e. $\quad f\left(X_{j}\right)$ $<f\left(X_{i}\right)$ for minimization problem, $X_{i}$ is moved towards $X_{j}$.

Otherwise it is moved away from $X_{j}$ :

$$
\begin{aligned}
\mathrm{X}_{\text {new }}=\mathrm{X}_{\mathrm{i}}+\mathrm{r} .\left(\mathrm{X}_{\mathrm{j}}-\mathrm{X}_{\mathrm{i}}\right) \text { if } & f\left(X_{i}\right)>f\left(X_{j}\right) \\
\mathrm{X}_{\text {new }}=\mathrm{X}_{\mathrm{i}}+\mathrm{r} .\left(\mathrm{Xi}_{\mathrm{i}} \mathrm{X}_{\mathrm{j}}\right) \text { if } & f\left(X_{i}\right)<f\left(X_{j}\right)
\end{aligned}
$$

Two learners ( $5^{\text {th }}$ and $10^{\text {th }}$ sequences) are randomly selected from the population (Table II) as an example.

(5- 14- 11- 8- 1- 12- 6- 9- 15- 2- 16- 13- 10- 3- 7- 4- 17) and (14- 8- 5- 11- 1- 9- 15- 12- 2- 6- 7- 10- 3- 16- 13- 17- 4)

If $\mathrm{f}\left(5^{\text {th }}\right.$ makespan $)<\mathrm{f}\left(10^{\text {th }}\right.$ makespan $)$ use $3^{\text {rd }}$ equation

$\mathrm{X}_{\text {new }, \mathrm{i}}=\mathrm{X}_{\text {old, } \mathrm{i}}+\mathrm{r}_{\mathrm{i}}\left(\mathrm{X}_{\mathrm{i}}-\mathrm{X}_{\mathrm{j}}\right)$

$\mathrm{X}_{\text {new }, \mathrm{i}}=(1-8-14-2-9-11-5-12-3-4-6-15-16-10-17-13-7)+0.85$

$\{(5-14-11-8-1-12-6-9-15-2-16-13-10-3-7-4-17)$ -

(14-8-5-11-1-9-15-12-2-6-7-10-3-16-13-17-4)

$X_{\text {new }, \mathrm{i}}=(1-8-14-2-9-11-5-12-3-4-6-15-16-10-17-13-7)+0.85$

(9-6-6-3-0-3-9-3-13-4-9-3-7-13-6-13-13)

$\mathrm{X}_{\text {new }, \mathrm{i}}=(1-8-14-2-9-11-5-12-3-4-6-15-16-10-17-13-7)+$

(8-5-5-3-0-3-8-3-11-3-8-3-6-11-5-11-11)

$\mathrm{X}_{\text {new }, \mathrm{i}}=$ 9- 13- 19- 5- 9- 14- 13- 15- 14- 7- 14- 18- 22- 21- 2224- 18

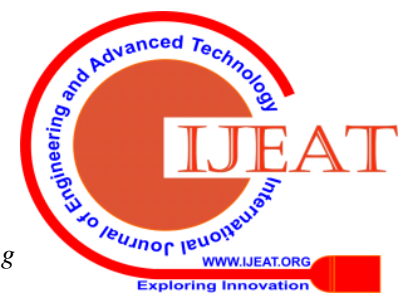




\section{Scheduling of Machines and AGVs Simultaneously in FMS through Hybrid Teaching Learning Based Optimization Algorithm}

Convert the values above 17 to allow max value within the bounds.

$\mathrm{X}_{\text {new } \mathrm{i}}=$ 9- 13- 2- 5- 9- 14- 13- 15- 14- 7- 14- 1- 5- 4- 5- 7- 1 In the above sequence few operations are missing and few are repeated. Hence it is repaired using the corrected repair function. The resulting sequence after repair is

$X_{\text {new, } i}=$ 9- 13- 2- 5- 10- 14- 11- 15- 16- 7- 17- 1- 6- 4- 12- 8- 3 This sequence is corrected by the repair function for precedence requirements and the output is

$\mathrm{X}_{\text {new }, \mathrm{i}}=$ 8- 11- 1- 5- 9- 14- 12- 15- 16- 6- 17- 2- 7- 3- 13- 104

If the makespan value of the new sequence (after learner phase) is less than the old sequence, the new sequence is stored in place of the old sequence. In case where the algorithm could not find a better sequence after learner phase, then it stores the original sequence (generated sequence).

Step 6: The above procedure has been applied for all 34 sequences and minimum make span values are found after 20 runs.

Step 7: After getting the final sequence from each iteration crossover and mutation concepts are utilized which were hired from sheep flock heredity algorithm as explained in detail in article IV section B
Step 8: Receptor editing:

The editing of the chromosomes in the population after the cross over operation is known as receptor editing. In this process a number of worst makespan value chromosomes are eliminated from the population and randomly generated chromosomes are added in those places. After editing the chromosomes in the population the new population has gone to next iteration until termination criterion is reached.

Step 9: Termination criterion:

The crossover, selection, mutation and receptor editing are repeated till the termination criterion is satisfied.

In the present work repeating the procedure for number of generations is taken as the termination criterion.

Step 10: The evaluated values of different parameters in arriving at the makespan after 1000 iterations for the best sequence is presented in Table III.

Table III shows scheduling of operations through hybrid teaching learning-based optimization algorithm for job set 9 layout 1.The operational completion time (makespan) is 116 minutes.

Table-I: data related jobset 9

\begin{tabular}{|c|c|c|c|c|}
\hline \multicolumn{9}{|c|}{ Job set : 9} & \multicolumn{2}{c|}{ No of operations: 17 } \\
\hline Layout: 1 & No of Jobs: 5 & Job 4 & Job 5 \\
\hline Job 1 & Job 2 & Job 3 & M2-M3-M4 & M3-M1-M2-M4 \\
\hline $1-2-3-4$ & M3-M2-M4 & M1-M2-M4 & $11-12-13$ & $14-15-16-17$ \\
\hline
\end{tabular}

Table-II : Generated population size for the HTLBO

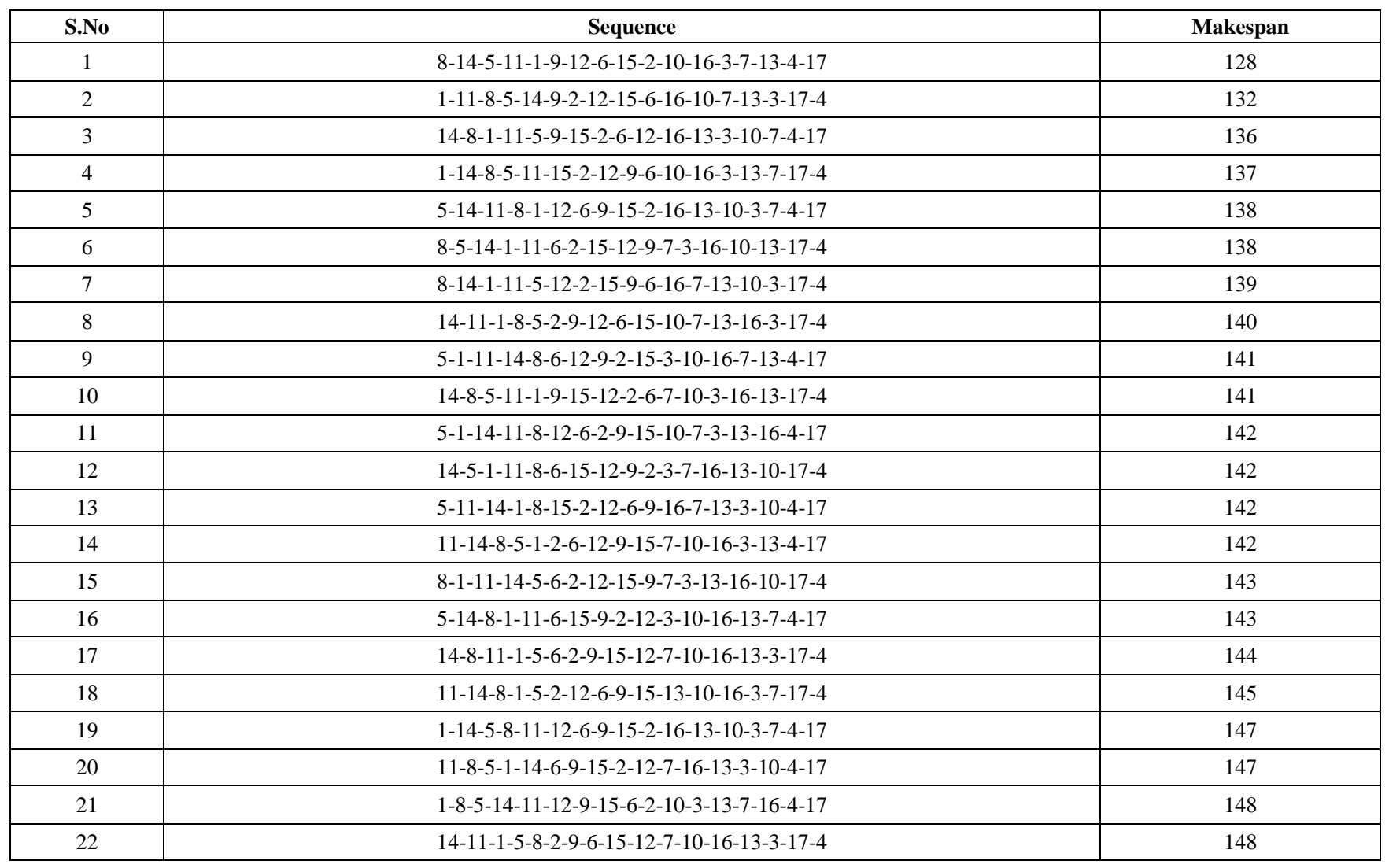




\begin{tabular}{|l|l|l|}
\hline 23 & $11-14-5-8-1-9-12-2-15-6-13-7-3-16-10-17-4$ & 148 \\
\hline 24 & $1-8-5-11-14-9-12-6-2-15-13-10-7-16-3-4-17$ & 149 \\
\hline 25 & $1-11-8-5-14-9-15-6-2-12-16-13-3-7-10-17-4$ & 150 \\
\hline 26 & $8-1-14-5-11-9-15-12-6-2-7-10-3-13-16-4-17$ & 150 \\
\hline 27 & $8-11-5-1-14-2-12-6-15-9-7-10-13-3-16-4-17$ & 151 \\
\hline 28 & $8-1-11-5-14-12-9-2-15-6-7-10-3-13-16-17-4$ & 152 \\
\hline 29 & $8-11-1-14-5-12-2-6-15-9-10-16-3-13-7-17-4$ & 152 \\
\hline 30 & $8-1-5-11-14-15-2-6-9-12-13-3-7-16-10-17-4$ & 154 \\
\hline 31 & $5-8-11-1-14-15-2-6-9-12-13-7-10-16-3-17-4$ & 154 \\
\hline 32 & $1-11-5-14-8-15-2-6-9-12-3-10-16-13-7-4-17$ & 156 \\
\hline 33 & $14-1-5-11-8-15-12-2-9-6-13-10-7-3-16-17-4$ & 158 \\
\hline 34 & $8-1-5-14-11-12-6-2-9-15-10-7-13-3-16-17-4$ & 163 \\
\hline
\end{tabular}

Table-III: Schedule Of Operations Through Htlbo ( Problem Set 9 And Layout 1)

\begin{tabular}{|c|c|c|c|c|c|c|}
\hline $\begin{array}{c}\text { Operation } \\
\text { Number }\end{array}$ & $\begin{array}{l}\text { Machine } \\
\text { Number }\end{array}$ & $\begin{array}{l}\text { Vehicle } \\
\text { Number }\end{array}$ & $\begin{array}{l}\text { Travel } \\
\text { Time }\end{array}$ & $\begin{array}{c}\text { Job } \\
\text { Reach }\end{array}$ & $\begin{array}{l}\text { Job } \\
\text { Ready }\end{array}$ & $\begin{array}{c}\text { Make } \\
\text { Span }\end{array}$ \\
\hline 5 & 3 & 1 & 0 & 10 & 10 & 26 \\
\hline 11 & 2 & 2 & 0 & 8 & 8 & 28 \\
\hline 14 & 3 & 1 & 18 & 28 & 28 & 42 \\
\hline 8 & 1 & 2 & 18 & 24 & 24 & 45 \\
\hline 1 & 3 & 1 & 36 & 46 & 46 & 55 \\
\hline 6 & 2 & 2 & 32 & 38 & 38 & 49 \\
\hline 12 & 3 & 2 & 38 & 44 & 55 & 77 \\
\hline 15 & 1 & 2 & 44 & 52 & 52 & 68 \\
\hline 9 & 2 & 2 & 52 & 58 & 58 & 76 \\
\hline 2 & 1 & 1 & 55 & 63 & 68 & 80 \\
\hline 7 & 4 & 2 & 58 & 66 & 66 & 75 \\
\hline 16 & 2 & 1 & 68 & 74 & 76 & 89 \\
\hline 13 & 4 & 2 & 77 & 83 & 83 & 94 \\
\hline 3 & 2 & 1 & 80 & 86 & 89 & 98 \\
\hline 10 & 4 & 1 & 86 & 94 & 94 & 101 \\
\hline 17 & 4 & 2 & 91 & 99 & 101 & 110 \\
\hline 4 & 4 & 1 & 102 & 110 & 110 & 116 \\
\hline
\end{tabular}

\section{RESULT AND DISCUSSION}

The results obtained using the proposed Hybrid Teaching Learning based Optimization (HTLBO) for the 82 problems, that is 40 problems done with $\mathrm{t} / \mathrm{p}>0.25$ and also 42 problems done with $\mathrm{t} / \mathrm{p}<0.25$ are presented in the below Tables IV and $\mathrm{V}$. Comparisions of these results with the results obtained by using priority rules proposed by (FCFS, SPT, LPT, Nageswararao et al. 2017) and results obtained using heuristics proposed by (NEH, Prakash babu et al, 2018, FUZZY, P. B. Kanakavalli et al, 2018) is also done and tabulated in Table IV and V. A code is used to designate the example problems which are given in the first column. The digits that follow 1.1 indicate the job set and the layout. In $\mathrm{t} / \mathrm{p}$ ratio $<0.25$ table another digit is appended to the code. Herehaving a 0 or 1 as the last digit implies that the process times are doubled or tripled- respectively- where in both cases travel times are halved.

Table-IV: Comparison of makespan values (for $t / p>0.25$ )

\begin{tabular}{|c|c|c|c|c|c|c|c|}
\hline Job. No & $\mathrm{t} / \mathrm{p}$ & FCFS & SPT & LPT & NEH & FUZZY & HTLBO \\
\hline 1.1 & 0.59 & 173 & 193 & 177 & 165 & 208 & $\mathbf{9 6}$ \\
\hline 2.1 & 0.61 & 158 & 158 & 177 & 169 & 170 & $\mathbf{1 1 3}$ \\
\hline 3.1 & 0.59 & 202 & 224 & 198 & 195 & 211 & $\mathbf{1 2 0}$ \\
\hline 4.1 & 0.91 & 263 & 267 & 264 & 260 & 268 & 17 \\
\hline 5.1 & 0.85 & 148 & 164 & 148 & 147 & 174 & $\mathbf{8 9}$ \\
\hline 6.1 & 0.78 & 231 & 240 & 227 & 225 & 233 & 196 \\
\hline 7.1 & 0.78 & 195 & 210 & 201 & 173 & $\mathbf{1 3 2}$ \\
\hline 8.1 & 0.58 & 261 & 261 & 266 & 261 & 261 & $\mathbf{1 3 5}$ \\
\hline
\end{tabular}


Scheduling of Machines and AGVs Simultaneously in FMS through Hybrid Teaching Learning Based Optimization Algorithm

\begin{tabular}{|c|c|c|c|c|c|c|c|}
\hline 9.1 & 0.61 & 270 & 277 & 268 & 259 & 273 & 116 \\
\hline 10.1 & 0.55 & 308 & 308 & 310 & 305 & 315 & 167 \\
\hline 1.2 & 0.47 & 143 & 173 & 165 & 147 & 188 & 82 \\
\hline 2.2 & 0.49 & 124 & 124 & 130 & 116 & 127 & 86 \\
\hline 3.2 & 0.47 & 162 & 188 & 160 & 154 & 178 & 96 \\
\hline 4.2 & $\begin{array}{l}0.73 \\
\end{array}$ & 217 & 223 & 224 & 215 & 232 & 90 \\
\hline 5.2 & 0.68 & 118 & 144 & 131 & 117 & 156 & 73 \\
\hline 6.2 & 0.54 & 180 & 169 & 165 & 158 & 175 & 108 \\
\hline 7.2 & $\begin{array}{l}0.62 \\
\end{array}$ & 149 & 160 & 149 & 136 & 139 & 91 \\
\hline 8.2 & 0.46 & 181 & 181 & 198 & 181 & 181 & 159 \\
\hline 9.2 & 0.49 & 250 & 249 & 244 & 205 & 249 & 104 \\
\hline 10.2 & 0.44 & 290 & 288 & 287 & 274 & 274 & 148 \\
\hline 1.3 & 0.52 & 145 & 175 & 167 & 145 & 190 & 84 \\
\hline 2.3 & 0.54 & 130 & 130 & 136 & 122 & 133 & 100 \\
\hline 3.3 & 0.51 & 160 & 190 & 162 & 158 & 176 & 102 \\
\hline 4.3 & 0.8 & 233 & 237 & 230 & 226 & 234 & 96 \\
\hline 5.3 & 0.74 & 120 & 146 & 133 & 117 & 156 & 76 \\
\hline 6.3 & 0.54 & 182 & 171 & 167 & 160 & 177 & 116 \\
\hline 7.3 & 0.68 & 155 & 166 & 151 & 138 & 141 & 104 \\
\hline 8.3 & 0.5 & 183 & 183 & 200 & 183 & 183 & 169 \\
\hline 9.3 & 0.53 & 252 & 251 & 246 & 207 & 251 & 106 \\
\hline 10.3 & 0.49 & 293 & 294 & 293 & 280 & 280 & 154 \\
\hline 1.4 & 0.74 & 189 & 207 & 189 & 189 & 228 & 104 \\
\hline 2.4 & 0.77 & 174 & 174 & 174 & 169 & 190 & 124 \\
\hline 3.4 & 0.74 & 220 & 250 & 212 & 213 & 225 & 130 \\
\hline 4.4 & 1.14 & 301 & 301 & 298 & 298 & 294 & 128 \\
\hline 5.4 & 1.06 & 171 & 189 & 171 & 171 & 193 & 97 \\
\hline 6.4 & 0.78 & 249 & 252 & 237 & 234 & 243 & 140 \\
\hline 7.4 & 0.97 & 217 & 242 & 151 & 192 & 232 & 154 \\
\hline 8.4 & 0.72 & 285 & 285 & 200 & 285 & 285 & 195 \\
\hline 9.4 & 0.76 & 292 & 311 & 290 & 285 & 295 & 123 \\
\hline 10.4 & 0.69 & 350 & 350 & 345 & 345 & 353 & 178 \\
\hline
\end{tabular}

Table - V: Comparison of makespan values (for $\mathbf{t} / \mathrm{p}<0.25$ )

\begin{tabular}{|c|c|c|c|c|c|c|c|}
\hline Job.No & $\mathrm{t} / \mathrm{p}$ & FCFS & SPT & LPT & $\mathrm{NEH}$ & FUZZY & HTLBO \\
\hline 1.10 & 0.15 & 207 & 248 & 252 & 207 & 278 & 126 \\
\hline 2.10 & 0.15 & 217 & 217 & 225 & 185 & 208 & 148 \\
\hline 3.10 & 0.15 & 257 & 327 & 282 & 255 & 300 & 162 \\
\hline 4.10 & 0.15 & 303 & 328 & 317 & 277 & 352 & 123 \\
\hline 5.10 & 0.21 & 152 & 190 & 187 & 154 & 225 & 102 \\
\hline 6.10 & 0.16 & 304 & 281 & 297 & 272 & 294 & 192 \\
\hline 7.10 & 0.19 & 231 & 240 & 264 & 213 & 235 & 137 \\
\hline 8.10 & 0.14 & 338 & 338 & 347 & 332 & 338 & 292 \\
\hline 9.10 & 0.15 & 390 & 367 & 359 & 324 & 382 & 182 \\
\hline 10.10 & 0.14 & 452 & 429 & 444 & 398 & 393 & 262 \\
\hline 1.20 & 0.12 & 194 & 238 & 246 & 197 & 268 & 123 \\
\hline 2.20 & 0.12 & 194 & 194 & 206 & 167 & 187 & 143 \\
\hline 3.20 & 0.12 & 241 & 311 & 270 & 241 & 285 & 159 \\
\hline 4.20 & 0.12 & 285 & 312 & 298 & 248 & 340 & 116 \\
\hline 5.20 & 0.17 & 142 & 180 & 184 & 143 & 217 & 100 \\
\hline 6.20 & 0.12 & 292 & 260 & 284 & 251 & 277 & 187 \\
\hline 7.20 & 0.15 & 212 & 218 & 249 & 188 & 210 & 136 \\
\hline 8.20 & 0.11 & 306 & 319 & 334 & 306 & 306 & 287 \\
\hline 9.20 & 0.12 & 380 & 355 & 347 & 309 & 372 & 179 \\
\hline 10.20 & 0.11 & 445 & 423 & 439 & 388 & 384 & 259 \\
\hline 1.30 & 0.13 & 195 & 239 & 247 & 196 & 169 & 122 \\
\hline 2.30 & 0.13 & 197 & 197 & 209 & 170 & 190 & 146 \\
\hline 3.30 & 0.13 & 240 & 312 & 271 & 240 & 284 & 160 \\
\hline 4.30 & 0.13 & 292 & 317 & 301 & 255 & 339 & 117 \\
\hline 5.30 & 0.18 & 141 & 181 & 183 & 143 & 216 & 99 \\
\hline
\end{tabular}




\begin{tabular}{|c|c|c|c|c|c|c|c|}
\hline 6.30 & 0.24 & 296 & 261 & 285 & 252 & 278 & 188 \\
\hline 7.30 & 0.17 & 215 & 221 & 250 & 191 & 213 & 137 \\
\hline 8.30 & 0.13 & 307 & 320 & 335 & 307 & 307 & 288 \\
\hline 9.30 & 0.13 & 381 & 356 & 348 & 310 & 373 & 180 \\
\hline 10.30 & 0.12 & 448 & 426 & 442 & 391 & 387 & 260 \\
\hline 1.40 & 0.18 & 213 & 255 & 254 & 213 & 288 & 124 \\
\hline 2.41 & 0.13 & 307 & 307 & 319 & 267 & 293 & 217 \\
\hline 3.40 & 0.18 & 261 & 330 & 282 & 258 & 305 & 162 \\
\hline 3.41 & 0.12 & 370 & 476 & 411 & 310 & 435 & 239 \\
\hline 4.41 & 0.19 & 434 & 471 & 451 & 393 & 504 & 177 \\
\hline 5.41 & 0.18 & 218 & 269 & 270 & 222 & 321 & 148 \\
\hline 6.40 & 0.19 & 310 & 288 & 299 & 275 & 303 & 189 \\
\hline 7.40 & 0.24 & 239 & 251 & 270 & 221 & 246 & 138 \\
\hline 7.41 & 0.16 & 329 & 344 & 385 & 224 & 332 & 203 \\
\hline 8.40 & 0.18 & 343 & 343 & 349 & 339 & 343 & 293 \\
\hline 9.40 & 0.19 & 396 & 379 & 370 & 325 & 388 & 182 \\
\hline 10.40 & 0.17 & 466 & 445 & 455 & 415 & 408 & 265 \\
\hline
\end{tabular}

Computations of completion times (makespans) for different combinations of job sets and layouts for Hybrid Teaching Learning Based Optimization algorithm, Priority rules (FCFS, SPT, LPT, Nageswara rao et al. 2017), Heuristic (NEH, Prakash babu et al, 2018, FUZZY, P. B. Kanakavalli et al, 2018) with $t / p>0.25$ are done and tabulated in Table IV. From Table IV it can be observed that, out of 40 problems, 40 problems gives better results using HTLBO when compared with all other five algorithms (100\%). Computations of completion time for

different combinations of job sets and layouts for Hybrid Teaching Learning Based Optimization algorithm, Priority

rules (FCFS, SPT, LPT, Nageswara rao et al. 2017), Heuristic (NEH, Prakash babu et al, 2018, FUZZY, P. B. Kanakavalli et al, 2018) with $\mathrm{t} / \mathrm{p}<0.25$ are done and tabulated in Table V. From Table V it can be observed that out of 42 problems, 42 problems give better results using HTLBO when compared with all other five algorithms (100\%).

\section{CONCLUSION}

Flexible Manufacturing system is considered as better option to face the challenges of global competition. But for successful implementation efficient scheduling is essential. Scheduling of an FMS is a very difficult problem because of other consideration like material handling. In this work an attempt has been made to solve the problem of scheduling both the machines and AGVs simultaneously by hybrid metaheuristic algorithm the following conclusions are drawn from this work. Performances of Hybrid Metaheuristic Algorithm is evaluated by considering 82 benchmark problems consisting of different job sets and layout configurations. From the comparison of these results Hybrid Teaching Learning Based Optimization algorithm (HTLBO) yielded improved results in 82 problems.

\section{SCOPE OF FUTURE WORK}

In this research work simulating metaheuristic Algorithms to solve simultaneous scheduling problems in FMS. There is scope for further research work in the following aspects: In FMS jobs are entered with different priorities and the problem can be made dynamic in nature.
When required sequence needs to reschedule. The simultaneous scheduling problem can be extended further by including AS/RS system. Real time issues like traffic jamming- without buffer space- machine breakdown can also be considered.

\section{REFERENCES}

1. Bilge, U., \& Ulusoy, G. (1995). A time window approach to simultaneous scheduling of machines and material handling system in an FMS. Journal of Operations Research, 43, 1058-1070.

2. Abdelmaguid, T. F., Nasef, A. O., Kamal, B. A., \& Hassan, M. F (2004). A hybrid GA / heuristic approach to the simultaneous scheduling of machines and automated guided vehicles. International Journal of Production Research, 42, 267-281.

3. Reddy, B. S. P., \& Rao, C. S. P. (2006). A hybrid multi-objective GA for simultaneous scheduling of machines and AGVs in FMS. International Journal of Advanced Manufacturing Technology, 31, 602-613.

4. Babu, A.G., Jerald, J., Haq, N., Muthu Luxmi, V., \& Vigneswaralu, T.P. (2010). Scheduling of machines and automated guided vehicles in FMS using differential evolution. Int. J. Prod. Res, iFirst, 1-17.

5. 5.Anandaraman, C., Vikram, A., Sankar, M., \& Natarajan, R. (2012). Evolutionary approaches for scheduling a flexible manufacturing system with automated guided vehicles and robots. International Journal of Industrial Engineering Computations, 3, 627-648.

6. Nouri, H. E., Driss, O.B., \& Ghédira, K. (2016). Simultaneous scheduling of machines and transport robots in flexible job shop environment using hybrid metaheuristics based on clustered holonic multiagent model. Computers, 488-501.

7. Amjad, K.M. et al. (2018). Recent research trends in genetic algorithm based flexible job shop scheduling problems. Mathematical Problems in Engineering, 1-32.

8. 8.Lundy, M., \& Mees, A. (1986). Convergence of an annealing algorithm. Math. Program, 34:111-124.

9. Rao, R.V., Savsani, V.J. and Vakharia, D.P., (2011), Teaching-learning-based optimization: A novel method for constrained mechanical design optimization problems, Computer-Aided Design, 43, 303-315.

10. Nageswara rao, M., Narayanarao, K., \& Rangajanardhana, G. (2017). Integrated Scheduling of Machines and AGVs in FMS by Using Dispatching Rules. Journal of Production Engineering, 20(1), 75-84.

11. .Prakash babu, K., Vijaya Babu, V., \& Nageswara Rao, M. (2018). Fuzzy heuristic algorithm for simultaneous scheduling problems in flexible manufacturing system. Management Science Letters, 8(12), 1319-1330. 
12. Prakash babu, K., Vijaya Babu,V., \& Nageswara Rao, M.(2018). Implementation of heuristic algorithms to synchronized planning of machines and AGVs in FMS. Management Science Letters, 8(6), 543-554.

13. Hyunchul, K., and Byungchul, A. (2001) .A new evolutionary algorithm based on sheep flocks heredity model, In: Pacific Rim Conference on Communications, Computers and Signal Processing, 2, 514-517.

\section{AUTHORS PROFILE}

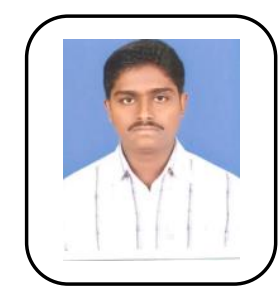

Kanakavalli Prakash Babu working as Assistant professor in Department of Mechanical Engineering V.R.Siddhartha Engineering College, Kanuru, Vijayawada. Persuing Ph.D in Andhra University. Areas of interest are Industrial Engineering, Quality control and Optimization techniques. Published 13 papers in many reputed journals and conferences

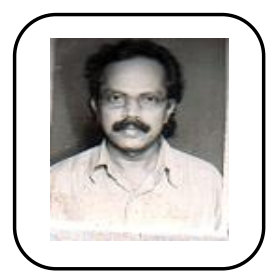

Vommi Vijaya Babu professor in Department of Mechanical Engineering, A.U.College of Engineering, Andhra University visakhapatnam Having more than 30 years of teaching experience. Published many papers in reputed journals. Area of interest are Industrial Engineering, SQC and Optimization Techniques

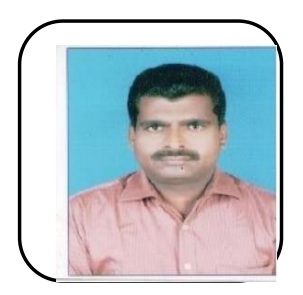

Medikondu Nageswara Rao received the Bachelor of Engineering degree from the GITAM College of Engineering, AP, India and the Ph.D. degree from JNTU, Kakinada, India. He is currently working as Associate Professor in the Department of Mechanical Engineering at in KLEF University, Guntur, AP, India. His research interests are in Artificial Intelligence \& Hybrid algorithms. published more than 27 papers in the Journals and conferences of repute. 